\title{
مدرسة الإسكندرية ونشأة الأفلاطونية الجديدة
}

\section{د. مصطفى مُحُمَّ قصيبات}

\section{كلية الآداب - جامعة مصراتة}

\section{مقدمة:}

يطلق اسم مدرسة الإسكندرية على ذلك التيار الفلسفي الذي ارتبطت نشأته بمدينة

Ammonius الإسكندرية، والذي كانت أهم الأسماء فيه أمونيوس ساكاس (175-242م)

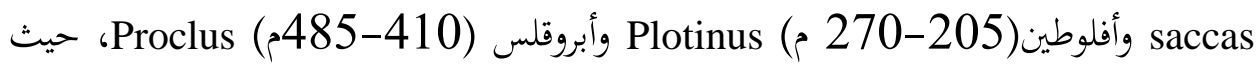
التقى العالم الإغريقي بالعالم الشرقي وحدث بينهما التقاء فكري خرج منه ما يمكن تسميته بالفلسفة الهلنستية(Hellenistic Philosoph من يهودية، وفيثاغورية محدثة، كما تم إحياء نزعة الشك ( النزعة الشكية ) بالإضافة إلى الأفلاطونية الجديدة أو مدرسة الإسكندرية(1). وقد أدت هذه التسمية -مدرسة الإسكندرية- إلى مظهرين من مظاهر الخلط: أولاً الخلط بين اسم مدرسة الإسكندرية، واسم الأفلاطونية الجديدة، فهل الأصح أن يرتبط هذا المذهب الفلسفي باسم المدينة التي وجد بها؟ وهل لهذه التسمية مبرراتا العقلية والتاريخية كما تفترض تلك المؤلفات التي تشير كلها إلى مدرسة الإسكندرية، حيث تتحدث عن الأفلاطونية الجديدة مثل: J. Simon, matter,Saint Hilire, Barthemy, Vacherot أن نلجأ إلى الأصل الفلسفي اليوناني فنسميها النيوبلاتونيزم New platunism أو الأفلاطونية

* - يلاحظ أن هناك فترتين للعالم اليوناين: فترة هلينية، وأخرى هلينستية، وتطلق الفترة الهلينية على العالم اليوناني وحضارته منذ الغزو الدوري حتى الإسكندر الأكبر، أي اعتباراً من القرن التاسع ق.م حتى سنة 336

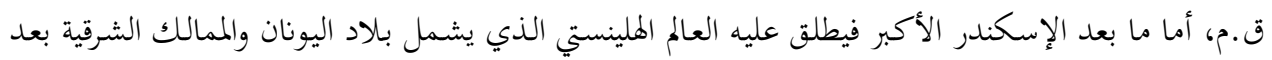
فتح الإسكندر لما. انظر

Toynbee, A., Hellensm: The history of civilization, London , 1959.

1- E. Zeller, Outliues of the history of Greek philosophy, London, 1931,p. 290. 
أما الخلط الثاني الذي ترتب على هذه التسمية، هو عدم التفرقة بين مدرسة الإسكندرية باعتبارها مدرسة فلسفية، وبين متحف الإسكندرية أو معهرها، ولم يفرق بين الإثنين حيث جعل من المدرسة الفلسفية في الإسكندرية فرعاً من فروع الدراسات التي ظهرت بالمتحف بل أقل هذه الفروع أهمية(1). وصفوة القول أن ليس هناك خطأ في تسمية المدرسة التي تركزت حول أفلوطين باسم "مدرسة الإسكندرية" وذلك لأن أفلوطين نشأ في الإسكندرية التي جمعت ثنافة الشرق والغرب، فكان إذن من الضروري الربط بين الفيلسوف وبين البيئة العقلية التي نشأ فيها (2). في هذه الدراسة سوف نسلط الضوء على مدرسة الإسكندرية ونشأة الأفلاطونية الجديدة من خلال النقاط الآتية:

أولاً: الحركة الفكرية في مدرسة الإسكندرية وأهم العوامل التي أدت إلى ظهور فلسفتها. ثانياً: مدرسة الإسكندرية، سماتها ومنهجها. ثالثاً: الفلسفة في مدرسة الإسكندرية. رابعاً: أبرز الشخصيات الفكرية في مدرسة الإسكندرية. خامساً: نشأة وخصائص الأفلاطونية الجديدة ومراحل تطورها. سادساً: الأفلاطونية الجديدة و تأثرها بالطابع الشرقي. و تأتي أهمية البحث في الوصول لإبراز مدرسة الإسكندرية حيث كانت نقطة الاتصال لمختلف الحضارات (حضارات العصر القديم، وحضارة مصر، وحضارة الشرق عامة، وحضارة اليونان) حيث تواعدت أو اتفقت هذه الحضارات معاً على اللقاء على ضفاف البحر المتوسط. ويي هذه الدراسة اعتمدنا على المنهج التاريخي التحليلي النقدي، ولا شك أنه يستقيم

1- M. Matter, Histoir del' ecole Alex, vol. 1,2 eme de paris, 1840, p. 160. 2- فئاد زكريا، التساعية الرابعة لأفلوطين في النفس، مراجعة مُحَّل سليم سالم، الهيئة المصرية العامـة للكتـاب، .32. 1970، صن. 
مع هذه الدراسة لنصل إلى خاتمة توضح أهم النقاط التي يمكن استخلاصها من الدراسة. أولاً: الحركة الفكرية في مدرسة الإسكندرية وأهم العوامل التي أدت إلى ظهور

فلسفتها:

نجد في الإسكندرية في القرن الأول المسيحي فلسفة دينية يهودية يحمل علمها فيلون اليهودي المعاصر للمسيح، والذي حاول المزج بين الفلسفة اليونانية والديانة اليهودية، ذاهباً إلى أن فلاسفة اليونان ما هم إلا متتلمذون على موسى والتوراة، كما نجد في القرن الثاني فلسفة دينية مسيحية حمل لواءها فلاسفة من اتباع مذهب أفلاطون، اعتنقوا المسيحية الحلديثة العهد، وكانت مضطهدة من حكام العالم الوطني الروماني فحاولوا الدفاع عنها، وتلقبوا بالمحامين عن المسيحية، وكان يعاصر حماة المسيحية جماعة الغنوصية أو العارفين وهم أسلاف المتوصفة، ويمثلون المحاولات

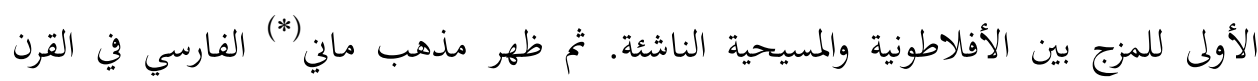
الثالث وهو يمزج الغنوصية والمسيحية بالعقيدة الزرادشتية القائلة بإلهين، إله الخير وإله الشر. ووي القرن نفسه ظهر في الإسكندرية حيث كانت المسيحية آخذة في الانتشار السريع فلسفة دينية مسيحية حمل علمها أكليمان وتلميذه أوريجين الإسكندريين، وقد مزجا بين المسيحية وفلسفة أفلاطون. وكان إلى جانبها في الإسكندرية فلسفة دينية وثنية صوفية متأثرة بتعاليم فيلون اليهودي، نشر مبادئها الفيلسوف المصري أمونيوس سكاس، تم تلميذه أفلوطين المصري الذي سيكون له أثر كبير في الفلسفة المسيحية(1). إن أهم العوامل التي أدت إلى ظهور فلسفة الإسكندرية تتمثل في الآتية:

* - مـاني بـن فاتكك الطقشوبن الذي ولـد في بابل حوالي 215م، كان متنسـكاً متصـوفاً متشـائماً لا يؤمن بانتصار الخير على الشر البتة، وقد تأثر مذهبه بالزرادشية وبالبراهمية الأولى والمسيحية قبل وضع الكنيسة، وقد قتله أحد ملوك الفرس سنة 275م. انظـر : حسربي عبـاس عطيتـو، خصائصـالفكر الفلسـفي في حضـارات الشـرق القـديم، دار المعرفـة الجامعيـة، الإسكندرية، "د.ط"، ص ص 103. 1 - عبده فراج، معالم الفكر الفلسفي في العصور الوسطى، مكتبة الأنجلو المصرية، 1969، ص4، صل 5. 


\section{أ- المؤلفات المرميسية: - المات}

تنسب المؤلفات الهرميسية إلى هرمس طوط (*) إله الحكمة والفنون في مصر القديمة، وقيل أها قديمة ترجمت من اللغة المصرية القديمة إلى اللغة اليونانية. ولكن ليس هناك ما يدل حقيقة على وجود تأليف باللغة المصرية القديمة نسب في عهد الفراعنة إلى الإله هرمس طوط هذا، بل إنه ليس هناك ما يدل على أن هذه المؤلفات كانت موجودة في العصر البطلمي، إلا إذا استثنينا بعض أجزائها اللخاصة بالتنجيم والكيمياء (1) والمحتوى الفكري لهذه المؤلفات الهرميسية مستمد من أصول يونانية ومن ثم ينتهي المؤرخون إلى أن مؤلفي هذه الكتب إما مصريون عرفوا لغة

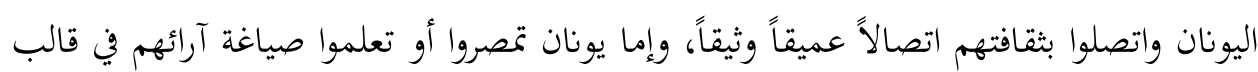
مصري شرقي، وهذا هو أرجح الأقوال (2). ويز لغة هذه المؤلفات تشابه واضح بينها وبين لغة التساعيات التي تلجأ دائماً إلى البدء بقول لأرسطو أو أفلاطون ثم تأخذ في التعليق عليه وكانت تقول لمعرفة صوفية ورؤى روحية أشبه بما انتهى إليه أفلوطين، وتتفق مع التيار الأفلاطوين في فكرة سقوط الإنسان وخطيئته فتقترب محا

ورد في محاورات الجمهورية وفيدون وفيدروس (3)

لقد انتشرت هذه المؤلفات المرميسية في العالم الإسلامي وأثرت في كثير من المفكرين الإسلاميين، أثرت في سلامان(*)وأبسال لابن سينا وحي بن يقضان لابن طفيل، والغربة الغربية

* - اسم إله من آلمة اليونان، ويعرف عند الرومان باسم Mercurius وهو عطارد عند العرب، ويزعم المصريون أنه نفس الإله تحوت Thot وينسبون إليه اختراع كل علم، ويطلق عليه أيضاً إدريس، وأخنوخ، وهرمس الهرامسة، ونه وهرمس المثلث بالنعمة ( انظر: ترجمته في الفهرست لابن النديم ص86، وفي طبقات الامهم ص18 وص39، وي الأخبار ص 1-7 ويذكره باسـم إدريس). ويـذكر أن هـمس يلقـب باليونانية (طريسميجيطس) أي ثلاثي التعليم لأنه يصف الباريء بثلاثة صفات ذاتية: الوجود والحكمة والحياة.

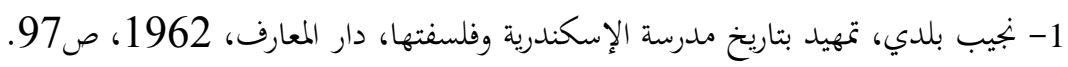

$$
\text { 2- المرجع نفسه، ص97-97-98. }
$$

3- أميرة حلمي مطر، الفلسفة عند اليونان، دار مطابع الشعب، 1965، صركسلة ص303. * - سلامان عند ابن سينا مثل للنفس الناطقة، وأبسال مثل للعقل النظري وهو درجتها في العرفان. 
للسهروردي، وكذلك في كتب الكثيرين من متصوفة الإسلام المتفلسفة. ولقد أثبتت الأبحاث العلمية الحديثة أن هذه الكتابات المرميسية من وضع أمونيوس ساكاس أول فلاسفة المذهبب

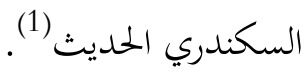

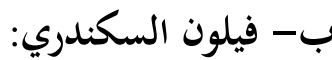

يعتبر فيلون السكندري أهم الشخصيات الفلسفية التي ظهرت في الفلسفة الهلينيستية اليهودية، ولد حوالي 25ق.م وتوفي 40م في الوقت الذي كان سفيراً ليهود الإسكندرية في عهد التيد الإمبراطور جايوس (2). تمثل فلسفته أهم محاولة للتوفيق بين الدين اليهودي والفلسفة اليونانية، ولجأ إلى التأويل الرمزي في فلسفته. أي أن فيلون لا يفصل في فلسفته بين الدين والفلسفة ولكنه يتخذ الدين أصلاً ويشرحه بالفلسفة(3). ويفسر فيلون العالم موفقاً بين التوراة والفلسفة اليونانية، إذ خلق الله عقلاً خالصاً في عالم المثل هو الإنسان المعقول ثم خلق على مثاله عقلاً أقرب إلى الأرض هو (آدم) وأعطاه الحس إنس

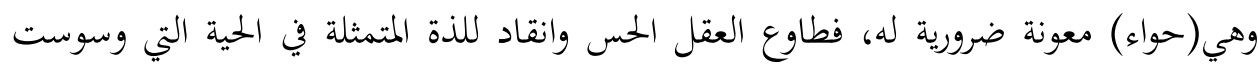
لحواء، فولدت النفس في ذاتها الكبرياء وهو (قابيل) وجميع الشرور، وانتفى منها الخير وهو (هابيل) وماتت موتاً خلقيّاً. ويؤل عبور البحر الأحمر بأنه رمز لخروج النفس من الحياة الحسية أو البدنية، وسبعة أغصان الشمعدان، بأهما رمز للسيارات السبع، والحجرين الكريمين اللذين يحملهما الكاهن الأكبر بأغما رمز للشمس والقمر أو لنصفي الكرة الأرضية، والآباء الذين يعود إليهم إبراهيم

1- علي سـامي البنشـار، نشـأة الفكـر الفلسفي في الإسـلام، الجـزء الأول، دار المعـارف، الطبعة الخامسـة، 224 1971

2- F.Copleston, S. J ., A history of philosoph, vol. Greece and Rome, New - york , 1962, pp.219-220.

$$
\text { 3- يوسف كرم، تاريخ الفلسفة اليونانية، 248. }
$$


بأغم رمز للكواكب أو للعناصر الأربعة أو للمثل، وشجرة الحياة في الفردوس الأرضي، بأها رمز

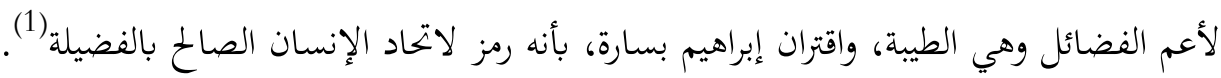
ثانياً: مدرسة الإسكندرية، سماتما ومنهجها:

اشتهرت الإسكندرية في القرن الثالث ق.م بمدارسها في عصر بطليموس الأول

(367قم-283قم)، ولعل أعظم هذه المدارس هي "المتحف" أو "الموزيم MUSEUM" التي أسسها بطليموس الأول وصارت أشهر مدرسة في الشرق. بجانب هذه المدرسة وجدت مده مدرسة السرابيوم "SERAPEUM" وأيضاً مدرسة سيباستيون "SEBASTION". وكان لهذه المدارس الثلاث مكتباهما الضخمة وضمت مكتبة المتحف وحدها مابين مائتي ألف ونصف مليون خخطوطاً وكتاباً. بجانب هذه المدارس انتشرت أيضاً مدارس يهودية تنشر الثقافة اليهودية في بقاع وضاع البلاد(2). وقد وصفها لاتوريت "LATORETTE" صارت مدينة الإسكندرية عالمية، وفيها

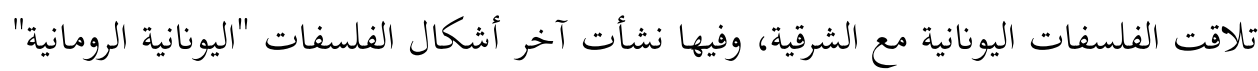
"GRECO - ROMAN" وفسر إيمانه الوراثي بطريقة يونانية. وفي المتحف "الموزيم" وجد ما يعادل الجامعة، وها شهرتا في

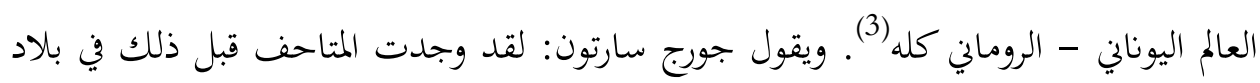
الإغريق فلم يكن المتحف إلا معبداً يوهب للآلهات أي ربات الشعر، والتاريخ، والفلك، ولكن متحف الإسكندرية كان معهداً من نوع جديد، بلغ أهميته بأن تغلغل اسمه في كثير من لغات

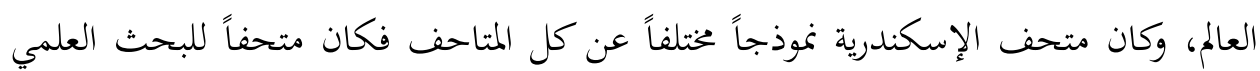
اهتم بعد ذلك بالفلسفة وغيرها من العلوم (4). وإن كان لا يوجد بالتفصيل صورة عن سمات المدرسة وبرابجها ومنهجها ومواد الدراسة

1- G . Bigg, Christian platonists of Alexandria, Oxford, 1913, p 26

2- H . M. Gwaktin, Early church History, London. 1909 Vol 2, p155.

3- K . S . Latourette, A history of Christianity, London 1953, p 146.

4- جورج سارتون، العالم القديم والمدينة الحديثة، ترجمة عبدالحميد صبره، مكتبة النهضة المصرية ، 1960، ص31. 
فيها، لكننا نستطيع أن نتكشف الخطوط العريضة من الذين كتبوا عنها ومن تراثهم الكتابي ومن شواهد المؤرخين. هذه الخطوط التي قيل عنها: لا يوجد نظاماً للتعليم الفلسفي أفضل محا كان

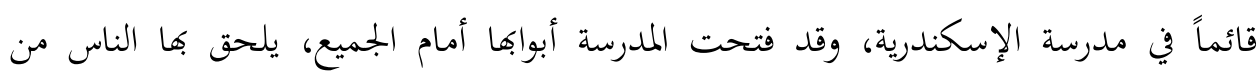
ديانات مختلفة وثقافات متباينة، وذو مراكز اجتماعية مختلفة وأعمار متفاوتة، وكان التعليم بها جامعياً وموحداً لا يميز بين الطبقات (1).

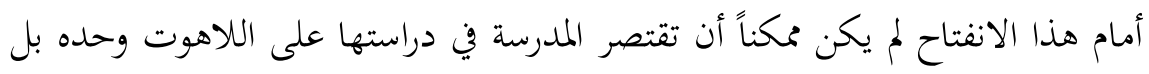
كانوا يدرسون الفلسفة والآداب والعلوم، وكان برنامجها منذ القرن الثاني مالم يكن منذ بلدء انطلاقها يقوم على أساس موسوعي Ency - clopedic وكان منهجاً تقليديّاً خاصّاً بالإسكندرية، وجد في مدارسها الوثنية واليهودية أيضاً، فكانت هذه المدرسة مركزاً للتعليم الفلسفي والعلمي كما للتعليم اللاهوتي (2). وقد وصفت هذه المدرسة في برابمها القوية بأن التعليم في سموه قد بلغ ابتحاهاً وشكلاً يقارب جداً نظام جامعاتنا الحديثة(3).

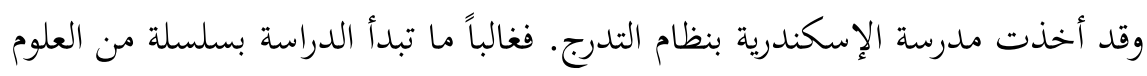

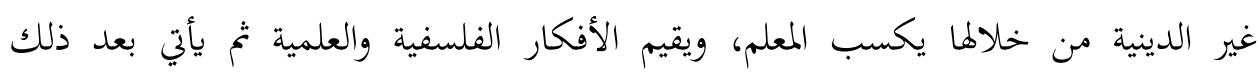
الأخلاقيات، والسلوكيات، ثم يدرس اللاهوت المسيحي ثم الفلسفة في شكل تعليقات وشروح. ويظهر هذا المزج في مراحله الثلاث من الكتب الثلاثة الرئيسية التي وضعها القديس "أكليمان

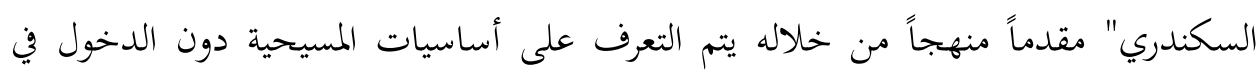
حرب مع الفلسفة. كما امتازت هذه المدرسة بعدم الفصل بين الدراسة والحياة الإيمانية، فكانت

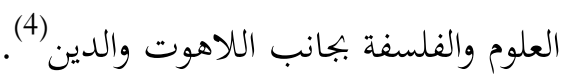

1- Rev . Markary EL- Souriany, Ancienty and contemporary Christian Education in the coptic church, Princeton, 1955, p 78.

2-Carls . Meyer, The church from pentecast to the present, Chicage 1970, p 39

3- W J. Cauhe, Didymus the blind, an aducatorat the forth century, Washington 1954, p36

4- Lebreton History of prinitive church, vol 3 , London 1946, p7323 


\section{ثالثاً: الفلسفة في مدرسة الإسكندرية:}

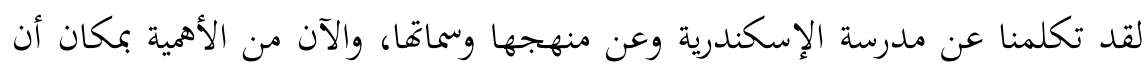
نعرف مكانة الفلسفة في هذه المدرسة، ويمكن أن نؤكد أن "المتحف" الذي وعني أنشأ جملة كراسي

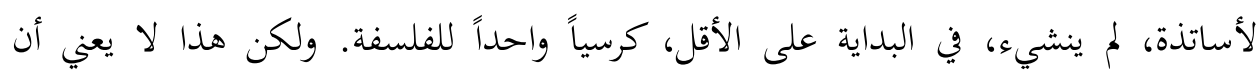

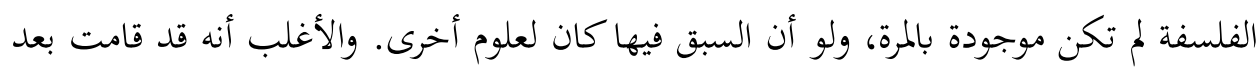
افتتاح المتحف في القرن الثالث قبل الميلاد مدارس خاصة للفلسفة، ومعلمون خصوصيون لها. بعضهم يمثل النزعة الأفلاطونية والبعض الآخر المشائية، والبعض الثالث الرواقية. ويمكن أن نؤكد

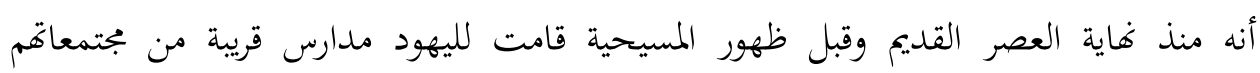
الدينية، تدرس فيها مباديء الفلسفة مع مباديء الدين والعلوم الأخرى، وشاهدنا على ذلك هو

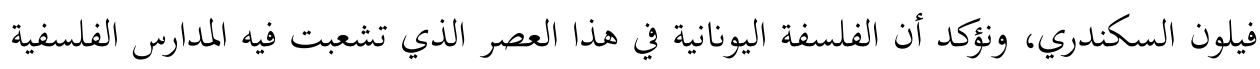
وتطاحنت، كانت مرتبطة بفنون الجدل والخطابة وأن هذه الفنون كانت تدرس بلإلمدارس

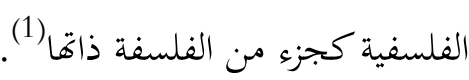
لقد أنشيء كرسي للفلسفة في متحف الإسكندرية، أو عدة كراسي والمعروف على وجه آله الدقة أن الفلسفة في آخر القرن الميلادي الثالث كانت ممثلة بمدارسها الأربع: الأفلاطونية

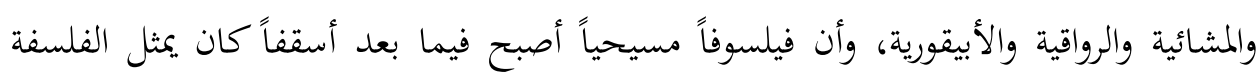
الأرسطية في المتحف. ولكن هذه الفلسفات التي كانت تعلم بالمتحف على كرسي رسمي

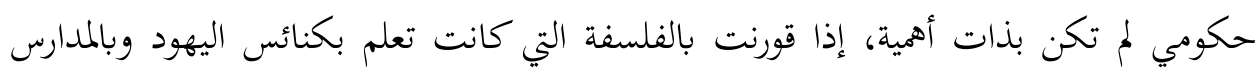

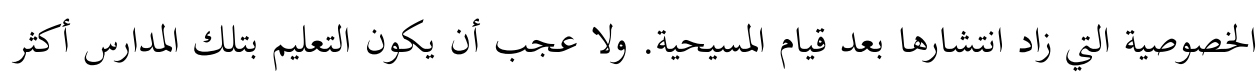
خطراً من التعليم الفلسفي بالمتحف الذي كان يلتزم بحرفية المذاهب الممثلة والتي كان متصلاً

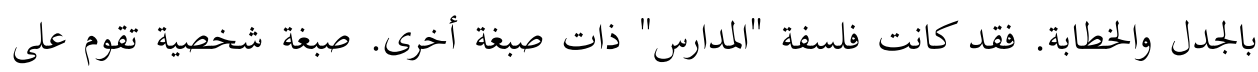
علاقة وثيقة بين المعلم والتلميذ، وكانت متصلة بالدين والنزعة الدينية أكثر محا كانت متصلة بالخطابة والجدل، ففلسفة الإسكندرية بالمعنى الدقيق لم تكن أصيلة كل الأصالة، ولم تكن مبتكرة

1- نجيب بلدي، مرجع سابق، ص51. 
لمعان جديدة أو لمذاهب متكاملة(1). يطلق في العادة على فلسفة الإسكندرية اسم "الأفلاطونية الحلديثة". ويدل هذا الاسم مداسم على قيام عاملين أساسيين فيها: عامل فلسفي أفلاطوني أصيل، ثم عامل أو عوامل أخرى، بعضها فلسفي وبعضها غير فلسفي أحدث في الزمن من العامل الأفلاطوين. ففلسفة الإسكندرية كما ستتمثل بوضوح عظيم عند أفلوطين بحمع بجانب فلسفة أفلاطون معان من عند أرسطو، ومعان أخرى من عند الرواقيين بعضها قديم يرجع إلى وقت تأسيس الرواقية من القرن

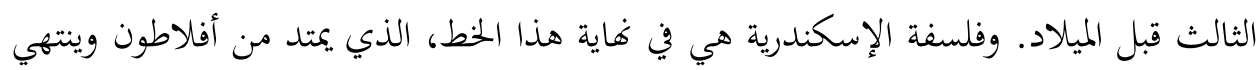

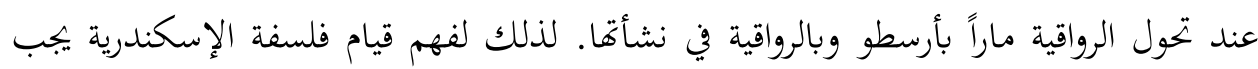

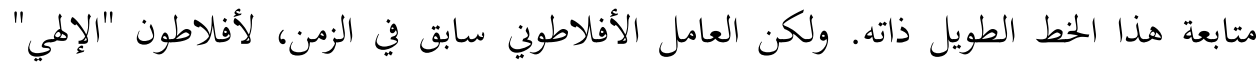
المنزلة الأولى في نشأة فلسفة الإسكندرية، فقد كانت هذه الفلسفة قبل كل شيء فلسفة دينية

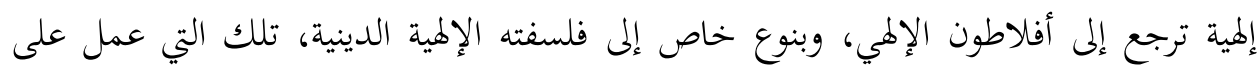

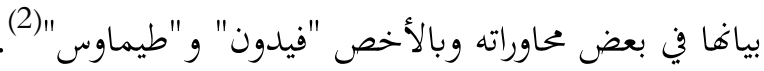

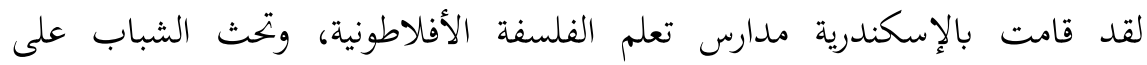
الاهتمام بهذه الفلسفة، واستمر هذا الإحياء حتى بلغ أسمى مرتبة عند "أمونيوس"(*) معلم

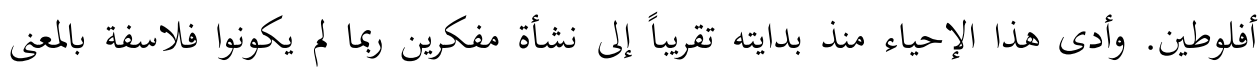
الدقيق، وإن كانت لهم أصالة واضحة في تفكيرهم وفي إفادقم من فلسفة أفلاطون التي تعلموها بالمدرسة، وي توجيههم تلك الفلسفة إلى أغراض لم تكن كلها فلسفية، ونقصد بهذا محثلين لهذا الفكر السكندري الذي قام بين فاية العصر القديم وفاية القرن الميلادي الثاني، والذي مهد مع

$$
\text { 2- 1- راجع المرجع نفسه، ص251. }
$$
* - أمونيوس ساكاس ولد في الإسكندرية نحو 175 م وتوفي عام 242م، لقب ساكاس أي الحمال لأنه

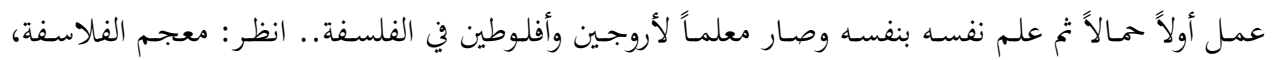

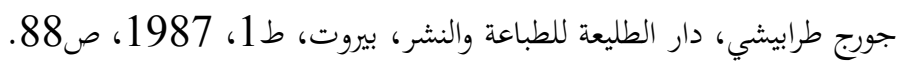


تعليم أمونيوس، لقيام فلسفة أفلاطونية في القرن الثالث. رابعاً: أبرز الثخصيات الفكرية في مدرسة الإسكندرية:

أثيناغوراس:

الفيلسوف أثيناغوراس رئيس مدرسة الإسكندرية هو أحد أبرز المدافعين عن الفلسفة المسيحية، فقد تحدث عن: الفلسفات بكوفا اعتمدت على العقل البشري وحده، فحملت

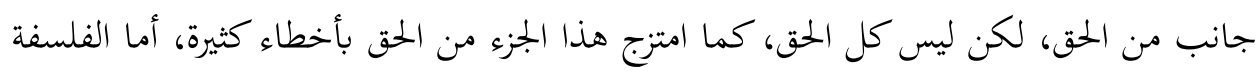
المسيحية فقدمت الحق خلال الله. فلهزا -حسب رأيه- فلا وجه للمقارنة بين المسيحية والفلسفة اليونانية، فالأولى إلهية والثانية بشرية(1). لقد تحدث عن المسيحية وكأها على قدم المساواة مع الفلسفة، وطالب الدهابه الدولة بالسماحة مع المسيحين (2).

تحدث الفيلسوف أثيناغوراس عن قيام الموتى في مقال يهوي 25 فصلاً، ويعتبر أول محاولة يقوم بها كاتب مسيحي ليؤكد عقيدة القيامة ببراهين فلسفية وليس بدلائل من الوحي

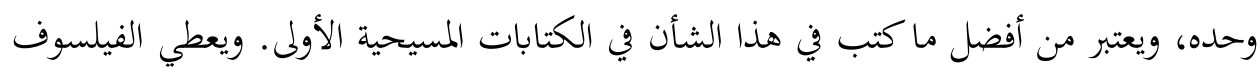
دلائل على القيامة:

أ- القيامة ضرورية لإٕنسان الذي خلقه الله كائناً عاقلاً ليعيش إلى الأبد. ب- يتكون الإنسان من الجسد والنفس. وهذه الوحدة يحطمها الموت لتعيدها القيامة من جديد فيحيا إلى الأبد. ج- ينبغي أن يشترك الجسد مع النفس في المكافأة في العالم الآتي كما اشتركا معاً في التصرفات هنا. د- خلق الإنسان من أجل السعادة الأبدية التي لا تتحقق بوجوده هنا على

1-Quasten, Patrology, vol 1, Oxtord Dict of the Christian church , p229.

2- Hanz Lietzmann, A history of the Early church , London 1974, vol 2, p186. 


\section{الأرض وإنما في الحياة الأخرى(1).}

أما عن فلسفة أثيناغوراس فكان فيلسوفاً ينتسب إلى الأفلاطونية الحديثة لكنه لم يخضع لما تماماً، خاصة بعد تحوله للإيمان المسيحي، إنما كان يتخير أفضل ما في المذاهب الفلسفية جميعها، حتى قيل عنه أنه أول القائلين بمذهب التخير و تأليف المذاهب، هذا المذهب في جوهره ينادي بأن كل مذهب يحمل نصيباً من الحقيقة هو خير ما في المذهب، لهذا لا يليق بالإنسان أن يطلب الحقيقة كاملة باختياره هذه الأجزاء وتوحيدها معاً، غير أن أثيناغوراس نادى بعجز

الفلاسفة عن الوصول إلى الحق كامالً، لذا وجدت ضرورة ملحة لهبوط الوحي على الأنبياء (2). القديس بنتينوس:

ولد بنتينوس في أوائل القرن الثاني الميلادي، وليس معروفاً على وجه الدقة تاريخ ميلاده

ووفاته، تولى الفيلسوف بنتينوس رئاسة مدرسة الإسكندرية حوالي عام 181م ونال شهرة فائقة حتى اعتبر أول رئيس للمدرسة وكان بنتينوس رواقياً مشهوراً. والرواقيون أخلاقيون من الدرجة الأولى يحسبون الخير الأعظم في الفضيلة، يؤمنون بناموس الطبيعة أو ناموس الضمير أو الواجب. يرون في الله الطاقة المتغلغلة في كل شيء، بها خلق العالم الطبيعي وبقي محفوظأ(3). اعتنق بنتينوس المسيحية عام 181م وإليه ينسب إدخال الفلسفة والعلوم إلى المدرسة لكسب الهراطقة والوثنيين المثقفين. كان بنتينوس دائم القراءة في الفلسفة ومع هذا لم يحتج عليه أهل عصره ولا اكموه بالانحراف عن الإيمان. أدخل القديس بنتينوس الأبجدية القبطية، مستخدماً اليونانية، مضيفاً إليها سبعة حروف من اللهجة الديموطيقية القديمة. وبهذا أمكن ترجمة الكتاب المقدس إلى القبطية تحت إشرافه و يعاونه في هذا العمل تلميذاه أكليمان وأورجين، كما ترجم القديس بنتينوس الكثير من الفلسفة والأدب المسيحي إلى هذه اللغة بكوها آخر شكل

1- S. Danie Lou, The Theology of Jewish Christianity, London 1964 , p 47 .

2- Schaff , History of Christian church , 1970, vol 2 , p732.

3- Coptic orth, Patriar chate, St Mark, cairo 1968, p 67. 
من تطور اللغة المصرية القديمة، وبدأ الكتاب يستخدموها عوض اليونانية(1).

\section{كلمنت الإسكندري (150-217):}

يعتبر كلمنت من أهم المدافعين عن المسيحية وكان لاهوتيّاً مسيحيّاً ينتمي إلى مدرسة

الإسكندرية، وولد من أبوين وثنيين، ودرس على عدة معلمين كان أهمهم الفيلسوف بنتينوس الذي تحول إلى مذهب الرواقيين وكان - كما سبق أن أشرنا- رئيساً للمدرسة(2). من أهم مؤلفاته الرئيسية كتاب "المدخل أو الهادي" قصد منه هداية الوثنيين إلى الإيمان بالمسيحية وإرشادهم إلى الحق (3) أما في كتابه "المتفرقات" عالج موضوعين رئيسيين هما: علاقة المتئ المسيحية بالفلسفة اليونانية، وعلاقة الإيمان بالمعرفة (الغنوصية)، وأجاب القديس كلمنت في أكثر من موضوع بشيء من التفصيل على السؤال الذي كان يشغل أذهان المفكرين المسيحيين في ذلك الوقت، ألا هو: ما هي النظرة المسيحية للفلسفة اليونانية (الهيلنية)؟ هل تمثل خطراً على الإيمان المسيحي أم هي معين له؟ لقد كان كلمنت الإسكندري يؤمن بأن دستور الكنيسة والكتب الدينية لا يتعارض مع الفلسفة وأنه لا عداوة بين المسيحية والفلسفة بل الفلسفة هي خادمة للدين، كما تكون الفنون الحرة الأخرى خادمة للفلسفة (4). أما عن خلاصة آرائه: فكان يرى أن الله هو خالق العالم والأساس المطلق لكل وجود، مصدر النور والحياة، لا بداية له ولا نهاية. ولا يخضع للزمن، وأنه واحد وبسيط لا ينقسم (5).

$1-$ I bid, p 68.

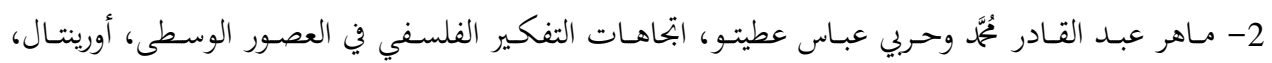

$$
\text { 3- المرجع نفسه والصفحرية، 2006، ص201. }
$$

4- انظر: أميرة حلمي مطر، الفلسفة عند اليونايين، دار مطابع الشعب، 1965، ص296. 5- Armstrong, A. H ., An Introduction to Ancient philosophy, london 1957, p 170. 
أما النفس الإنسانية عنده فكان يظن أها مادية ولكنه يجعلها لطيفة إلى حد بعيد

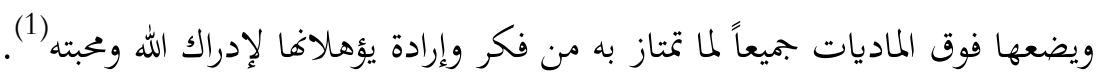

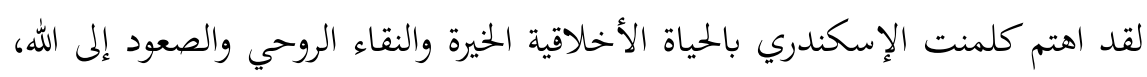
و تأثر في آرائه الأخلاقية ببعض مذاهب اليونان، فعن أفلاطون تأثر بالرأي القائل العلم فضيلة

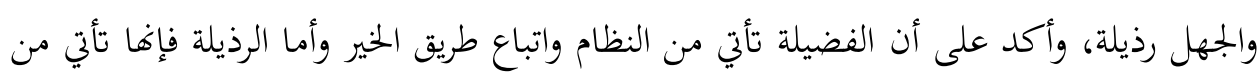

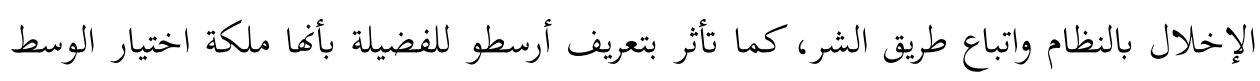

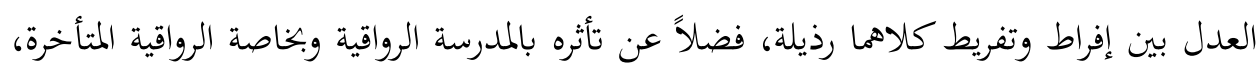
فأخذ عنها تحليلها الدقيق للفضائل والرذائل (2).

\section{أوريجين الإسكندري(185م-254 م) مانهائ}

ولد في الإسكندرية نحو سنة 185م من والدين فاضلين، وكان والده عالماً فغرس في

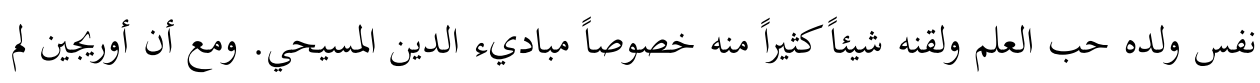
يكن قد بحاوز الثامنة عشر من عمره فقد اجتذب علمه وبلاغته كثير من الطلاب وثنيين

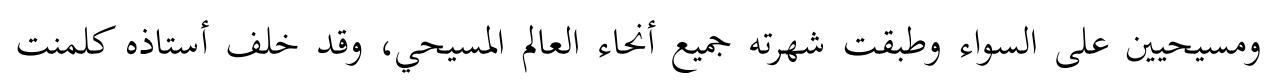
على رئاسة المدرسة(3).

استخدم أوريجين الفلسفة في تفسير العقائد الدينية ففسر ما جاء في سفر التكوين

(( في البدء خلق السموات والأرض، بأهما لا تعني أنه خلقها في الزمان بل الأزل؛ لأن الله لا

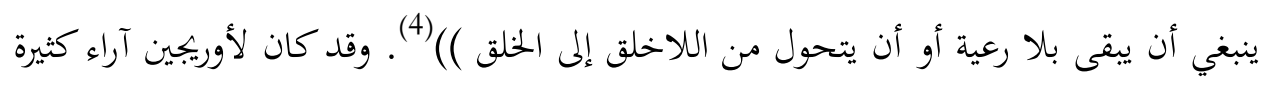

$$
\text { 1- يوسف كرم، تاريخ الفلسفة اليونانية، دار المعارف، ط6 ، ص273. }
$$

2- Armstrong, A, H . Op cit, p 171.

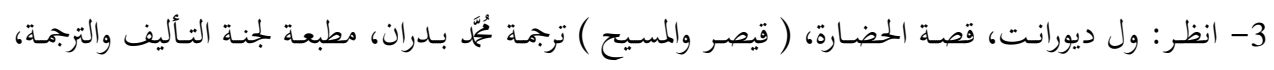

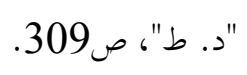

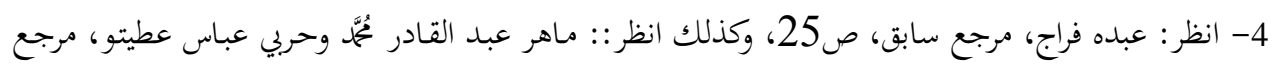
سابق، ص205. 
في الألوهية (وجود الله والعالم والإنسان)، وأخرى في الخلق والمعاد وغيرها. ويهتم أوريجين بتحديد

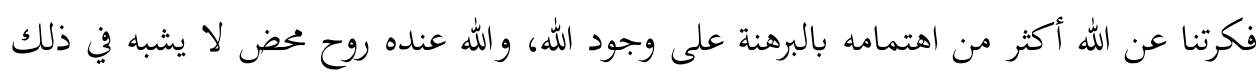
مخلوق وأنه روح عاقل حر غير منظور وهو فوق جميع مقولاتنا من حقيقة وحكمة ونور وحياة

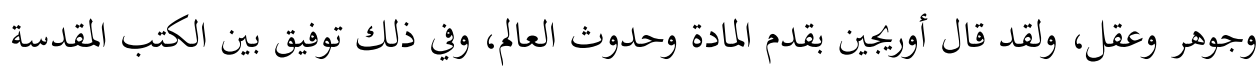

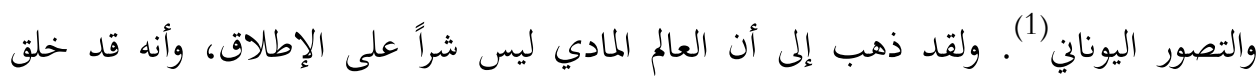
بواسطة الله لا عن طريق قوى شريرة(2).

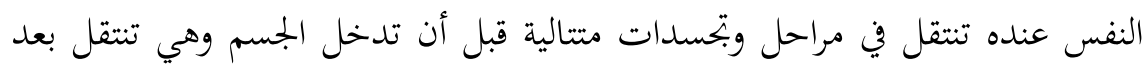
الموت في مراحل متتالية مثلها قبل أن تصل إلى الله وأن جميع الأنفس حتى أطهرها تتعذب زئل زمناً في المطهر ولكنها كلها تنجو آخر الأمر، وسيكون بعد اللهب الأخير عالم آخر ذو تاريخ طويل

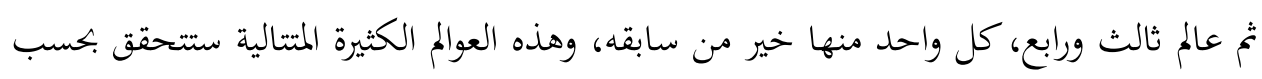

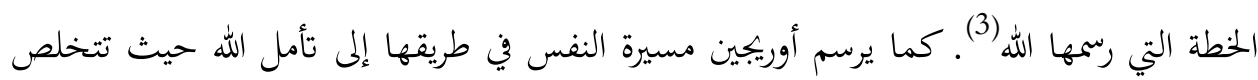

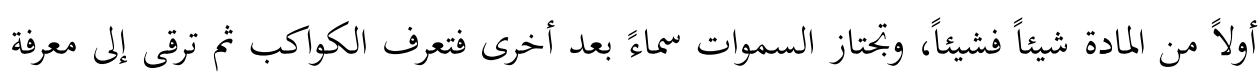
غير المنظورات وترقى حتى تصل إلى المرحلة الأخيرة وهي تأمل الله (4).

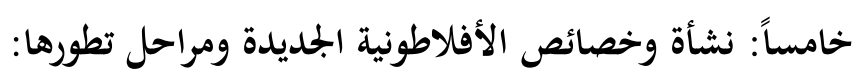
أ- النشأة والخصائص: من أهم الاتجاهات الفلسفية التي ظهرت بالإسكندرية هو مذهب الأفلاطونية الجديدة،

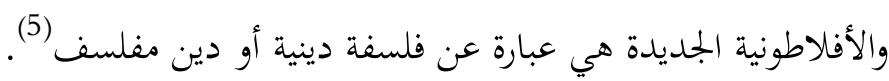
وتركزت عنايتها في محاولة إنتاج مذهب فلسفي يمكن أن يلبي مطامح الإنسان الروحية

$$
1 \text { - يوسف كرم، مرجع سابق، ص279. }
$$

2- Armstrong . A . H . Op. cit, p 174.

$$
\begin{aligned}
& \text { 3- ماهر عبد القادر مُحَّمَ وحربي عباس عطيتو، مرجع سابق ص206 - } 207 . \\
& \text { 4- يوسف كرم، مرجع سابق، ص283. }
\end{aligned}
$$

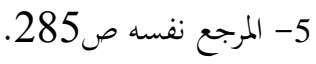


جميعاً، عقلية ودينية وأخلاقية بتقديم صورة شاملة ومتسقة منطقياً للكون وكيفية استعادة توازنه وحالته الأصلية المفقودة(1). ولقد قام هذا المذهب على أصول أفلاطونية ومن هنا جاءت تسميته بالأفلاطونية الجديدة(2) ويدل هذا الإسم على قيام عاملين أساسيين فيها: عامل فلسفي أفلاطوني أصيل، ثم عامل أو عوامل أخرى، بعضها فلسفي أحدث في الزمن من العامل الأفلاطوني، وهذه الفلسفة كما ستتمثل بوضوح عظيم عند أفلوطين بتمع بجانب فلسفة أفلاطون معانٍ عند أرسطو، ومعانٍ أخرى من عند الرواقيين بعضها قديم يرجع إلى وقت تأسيس الرواقية في القرن الثالث قبل الميلاد، وبعضها أقل قدماً يرجع إلى تطور الرواقية أثناء القرن الثاني قبل الميلاد(3) . ومن هنا فبان الأفلاطونية الجديدة تمثل عناصر من جميع المذاهب الفلسفية والدينية يونانية وشرقية بما في ذلك السحر والتنجيم والعرافة(4).

والمؤسس الشهير لذذا المذهب هو أمانيوس ساكاس لكننا يمكن أن نتجاوزه ونصل إلى تلميذه أفلوطين الذي كان أول من طور الأفلاطونية الجديدة وتحويلها إلى مذهب ولقد كان أعظم عارض للمذهب بل وربما يعد المؤسس الحقيقي له. ولقد ولد أفلوطين عام 205 بعد الميلاد في ليقوبوليس بصعيد مصر وذهب إلى روما عام 245 وأسس مدرسة هناك وظل على رأسها حتى وفاته عام 270 (5). ولقد اختلفت وجهات نظر المؤرخين بصدد الأفلاطونية الجديدة، فالبعض ينكر كوها فلسفة يونانية، مستندين في ذلك إلى بعد الزمن بين العهدين ولأن مؤسسها هو أفلوطين الذي

$$
\begin{aligned}
& \text { 1- ماهر عبد القادر عُمَّمّ وحربي عباس عطيتو، مرجع سابق، ص70. } \\
& \text { 2- يوسف كرم، مرجع سابق، ص285. } \\
& \text { 3- نجيب بلدي، مرجع سابق، ص52 } \\
& \text { 4- يوسف كرم، مرجع سابق، ص285. }
\end{aligned}
$$

5- وولتر ستيس، تاريخ الفلسفة اليونانية، ترجمة بجاهد عبد المنعم بجاهد، دار الثقافة للنشر والتوزيع، القاهرة، 1984، صو303. 
ولد عام 205م، فهذه الفلسفة إذن وليدة المسيحية، فضلاً عن أن طابع هذه الفلسفة ليس إغريقياً بحثاً وإنما هو مصبوغ بصبغة الإلمام الشرقي، كما أن مركزها كان في الإسكندرية لا في إنان

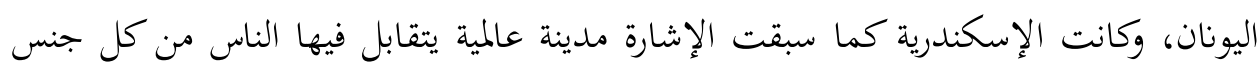
ويلتقي فيها الشرق بالغرب. والبعض الآخر يرى أن الأفلاطونية الجلديدة لا تنتسب إلى العصور الوسطى لأن الأخيرة

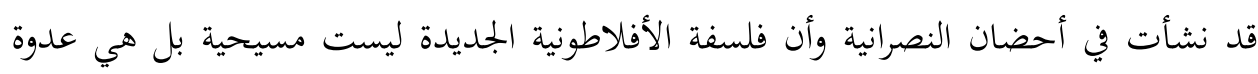
للمسيحية، وعلى ذلك فمن الأولى أن تعد فلسفة يونانية(1).

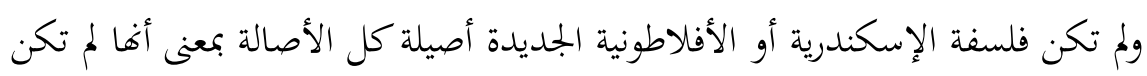

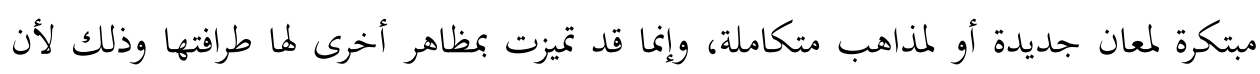

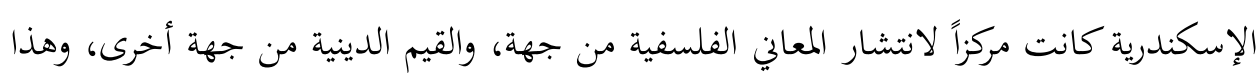
ما يسمى بالتوفيق والتلفيق (2) ولقد قدر لهذا المذهب أن يتشكل في سوريا وروما وأثينا بعض التشكل مع الحفاظ على ولى الطابع الصوفي المميز له في كل مكان. ففي روما اتخذت الأفلاطونية الجديدة على يد زعيمها "فورفوريوس الصوري"(*) شكلاً

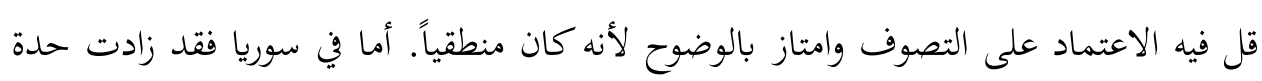

1- أحمــ أمسين، وزكي نجيب محمود، قصـة الفلسفة اليونانية، مطبعة دار الكتب اليونانيـة، ط 2 ، القـاهرة،

$$
\text { 20 1970، نجيب بلدي، مرجع سابق، ص6266. }
$$

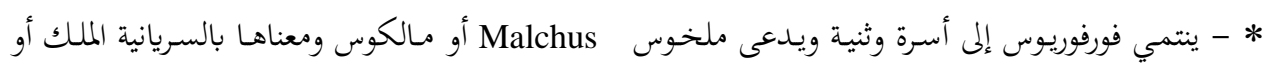

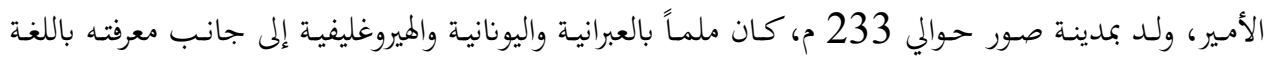

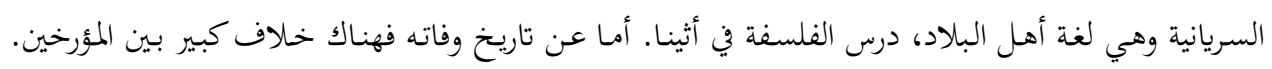

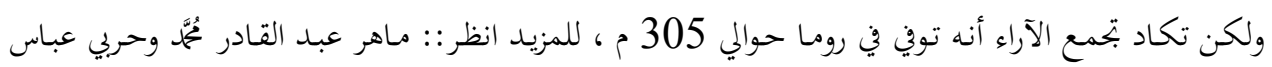

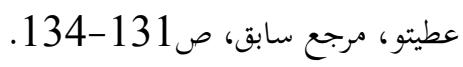


النزعة الدينية في الأفلاطونية الجلديدة وازدادت غموضاً على يد "يامبليخوس"(*) أما "أبروقلس" فيعتبر ممثل للأفلاطونية الجلديدة في أثينا حيث اشتد العداء بين الأفلاطونية الجلديدة والمسيحية

واشتدت حماستها للموسوية والوثنية(1). ولعل أهم ميزة تتسم بها الأفلاطونية الجلديدة هي الذاتية المطلقة، تلك الميزة التي تستطيع تمييزها تمييزاً واضحاً عن الفلسفة اليونانية الحقيقية. فضلاً عن أن هذه الفلسفة تأثرت منذ البداية بالتجربة الدينية وبخاصة التجربة الصوفية، وهذا الطابع الجمديد لا نكاد نجده في الفلسفة اليونانية الحقيقية (2)

\section{ب. مراحل تطورها: - ما:}

لقد أشرنا إلى أن الأفلاطونية الجديدة هي محاولة لوضع فلسفة دينية، أو دين مفلسف ألفا وقد نجحت في إدماج الفكر الفلسفي المبكر وخاصة أرسطو والرواقية والفيثاغورية مع استبعاد فكر الأبيقورية، نجحت في إدماج كل ما تقدم من فلسفات بالأفلاطونية. كما أن الأفلاطونية الجديدة تمثلت كثيراً من المعتقدات الدينية والأساطير والطقوس والعلوم القديمة كالكيمياء والأعمال السحرية التي تقوم في أغلب الأحيان على الصلات بين الكواكب والمعادن. ويذكر المؤرخ الألماني Fr. Uerweg أن الأفلاطونية الجديدة محاولة فلسفية لإيجاد محيط عام يدخل فيه ما نقل من الآراء الفلسفية والدينية الإغريقية أو الشرقية الأصل، وكانت عنايتها بالجانب الإلهي من هذه الثقافات المختلفة أكثر من غيره(3). والأفلاطونية الجديدة هي إسكندرية وسورية وأثينية(4) وقد مرت في تطورها بأدوار ثلاثة

* - سنأتي على ذكره عند الحديث عن الدور الثاني من أدوار تطور الأفلاطونية الجديدة. 1- Copleston , op. cit , pp 216, 217

2- عبد الرحمن بدوي، خريف الفكر اليوناني، مكتبة النهضة المصرية، ط 4 ، 1970، ص114، 115. 3- Fr. Ueberweg , Outline of philosophy Since the beginning of Sixth Century, translated by Heineze, p. 599.

$$
\text { 4- يوسف كرم، مرجع سابق، ص285 . }
$$




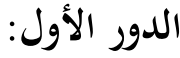

ويمثله أفلوطين (205-270م) وتلميذه فورفوريوس والغاية منه إحداث التوازن بين الدين والفلسفة(1)، فلو تأملنا فلسفة أفلوطين مثلاً سنجد أها تدور حول مشكلنين وندين أساسيتين هما مشكلة دينية تتعلق بمصير النفس وطريق إعادها إلى طهارتا الأولى، ومشكلة أخرى فلسفية

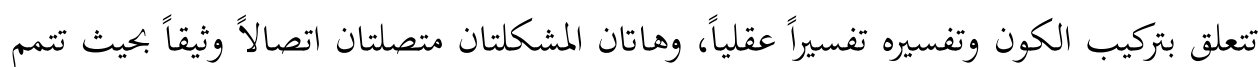
الواحدة الأخرى(2). وفي هذا الدور وضعت كل المسائل الرئيسية التي قالت بها الأفلاطونية الجلديدة، كما ظهرت كل المباديء الميتافيزيقية التي تقوم عليها وتحددت الصلات المتعددة التي توجد بين الفلسفة وبين بقية أجزاء العلم (3). فالصلة بين الدين والفلسفة إذن لم تكن طغيان من جانب الدين الدين على الفلسفة، وإنما كانت صلة توازن، حتى إن الدين كان لا يشغل كل الفلسفة في ذلك العصر.

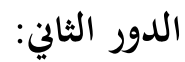

ويمثله يامبليخوس (270-330 م) وفي هذا الدور يسيطر الدين على الفلسفة.

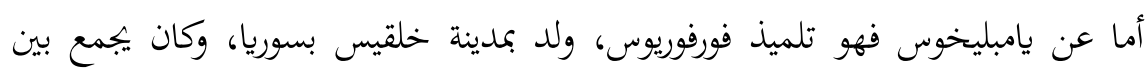
الدين والفلسفة كما كان يقرأ لأفلاطون وأرسطو ويربطهما بفيثاغورس ثم يتجه إلى تفسير هذا المزيج تفسيراً يتفق مع أديان الشرق وتصوفه والتراث السحري للعالم القديم، وقد كتب في الفلسفة والرياضة

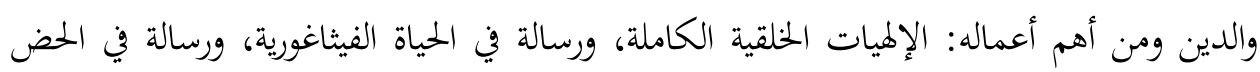
على الفلسفة وكتاب العلم الرياضي بالإجمال، والمدخل لكتاب نيقوماخوس في الحساب، وكتاب إلماب جملة آراء فيثاغورس، وكتاب أسرار المصريين أي معتقداهم الدينية(4).

1- Fr. Uberweg, op. cet. P.599.

2- انظر: حنا الفاخوري وخليل الجر، تاريخ الفلسفة العربية، الجزء الأول، دار المعارف بمصر، ط1، 1957،

$$
\text { 3- انظر: عبد الرحمن بدوي، مرجع سابق، ص98. }
$$

4- John . E. Erdmann, A history of ph: Losophy, vol 1, Translated by W. T. , Hough.1899.p297. 
ويتضح لنا مما تقدم أن يامبليخوس كان يمزج بين الدين والفلسفة والرياضة، ولعل هذا

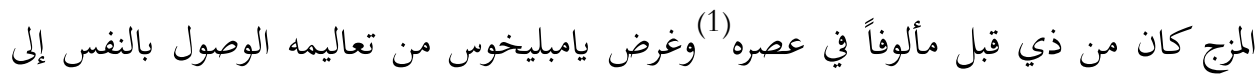
الاتحاد التام بالله، والوحي الإلهي هو الذي يعلمنا كيف نبلغ هذا المقام، ومن ثم كان الكهنة أعلى مرتبة من الفلاسفة باعتبارهم حاملي الوحي الإلهي، وهم أيضاً الذين يعلمون الإنسان

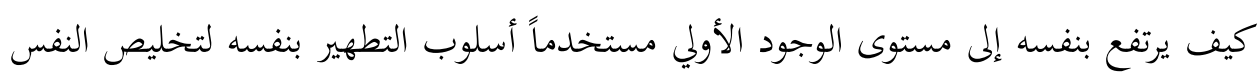
من الجسد وعلائقه الدنيئة(2).

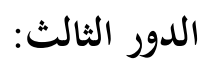

أبرز مفكري هذا الدور أبروقلس (410-485م) وهو أحد فلاسفة الأفلاطونية

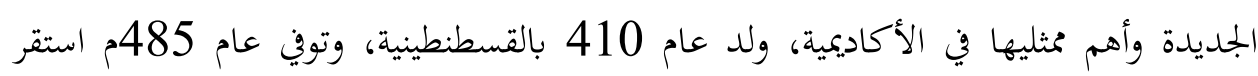
بأثينا وهو في العشرين من عمره وتزعم رئاسة هذه المدرسة، وقد ترك عدداً من المصنفات أهمها شروح على محاورات أفلاطون وشرح على مباديء أقليدس الرياضي، ويعتبر كتاب عندمن وناصر الثيولوجيا(*) أهم مؤلفاته جميعاً(3) ويمثل أبروقلس الدورج على مبادئ الأخير من مراحل تطور الأفلاطونية

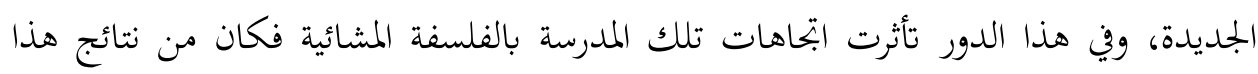
التأثير أن أصبحت أكثر تنظيماً وأدق تعبيراً، وهكذا يكون قد طرأ على الأفلاطونية الجديدة تطور جديد حين امتزجت بفلسفة أرسطو (4).

$$
\text { 2- 1- يوسف كرم ، مرجع سابق، ص298. }
$$

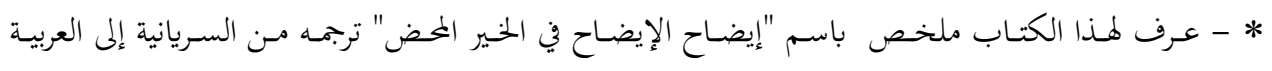

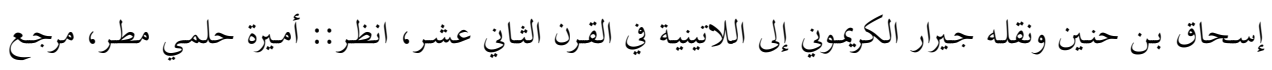
سابق، ص2315. 3- F. Copleston, op.cit. , p 221.

$$
\text { 4- انظر : يوسف كرم ، مرجع سابق، ص303. }
$$




\section{سادساً: الأفلاطونية الجحديدة وتأثرها بالطابع الشرقي:}

أما عن مدى تأثر الأفلاطونية الجديدة بالروح الشرقية أو الطابع الشرقي، فهذه مسألة تتنازعها الآراء وتختلف حوها وجهات النظر، حيث ينكر فريق من المؤرخين أثر المؤثرات الشرقية في تلك الفلسفة ومن هؤلاء المؤرخين تسلر Zeller، أما الذين يؤكدون على أهمية المؤثرات

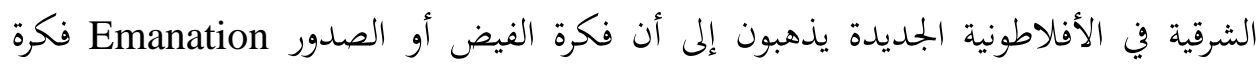

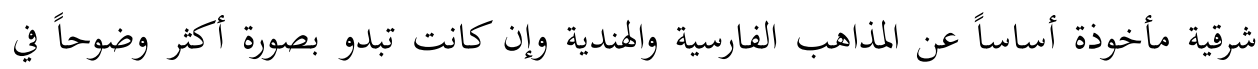
بعض المذاهب الهندية رغم أن أفلوطين لم يسافر إلى الهند، ولم يلتق بأي من الأفكار الشرقية ولم

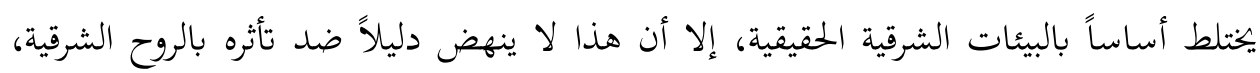
فقد وجدت هذه العناصر الشرقية في القرون الثلاثة الأولى للميلاد على وجه الخصوص وانتشرت

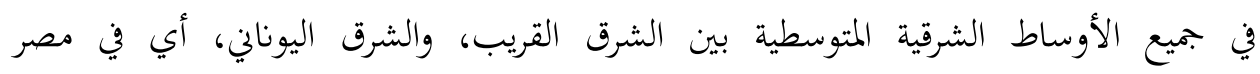

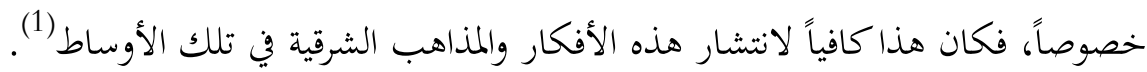
فلا سبيل إذن إلى إنكار تأثر الأفلاطونية الجديدة بالأفكار الشرقية. ولعل من أكثر الأفكار تأثيراً على الأفلاطونية الجديدة هو الغنوصية، والغنوصية مشتقة من الكلمة اليونانية gnosis ومعناها

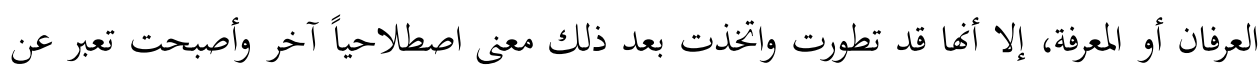

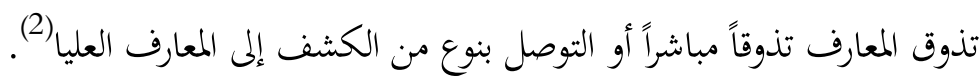

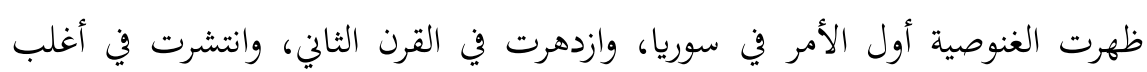

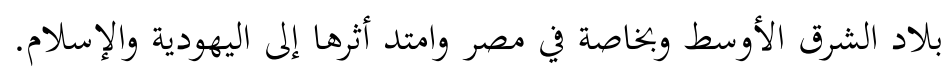

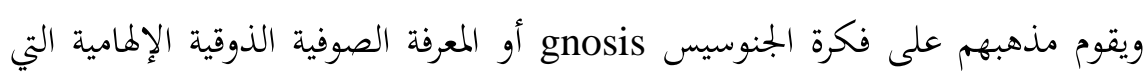
تمدف إلى الخلاص من العالم الحسي والاتحاد بالله. وتتشابه الغنوصية مع الأفلاطونية الجلديدة في عدة مسائل إلا أن طريقة تناول هذه المسائل مختلفة عند كل منهم (3).

$$
\text { 1- 1 - عبد الرحمن بدوي، مرجع سابق، ص115-116. }
$$

2- The Encyclopaedia of philosophy, art vol .3,4, New York, 1972, p336.

$$
\text { 3- انظر : عبد الرحمن بدوي، مرجع سابق، ص96-98. }
$$




\section{ـ المسألة الأولى:}

"مسألة الواحد" ينكر الغنوصيون إمكان وصف الله بأية صفة من الصفات (الإيجابية أو

السلبية) وهذا قريب الشبه بأفلوطين.

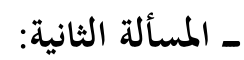

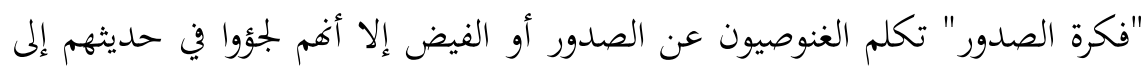

أساليب رمزية أسطورية غامضة، كما أفم عمدوا إلى تصورات غير دقيقة مما تعذر عليهم توضيح كيفية هذا الصدور.

لكن أفلوطين وإن كان قد تحدث عن الفيض الإلهي إلا أنه قد تفوق عليهم تفوقاً كبيراً واستطاع أن يكون نسقاً، يبدأ من الواحد ماراً بالعقل الكلي ثم النفس الكلية ثم النفوس الجزئية الجمئ

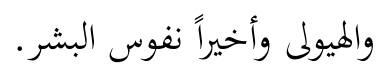

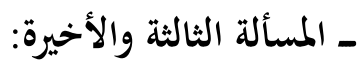

"فهي تتعلق بفكرة الهيولى" فلقد جعل الغنوصيون الهيولى أو المادة شيئاً مشتقاً من الميارة

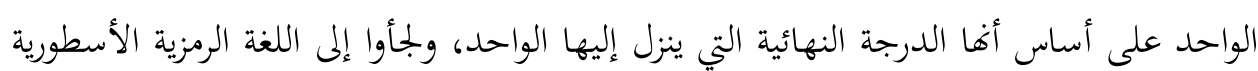
مما استحال معه أيضاً توضيح كيفية الصلة بين المادة وبين الله.

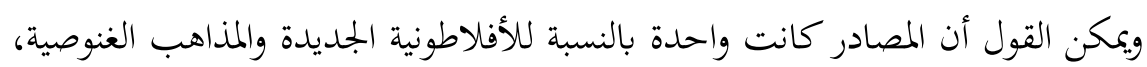
فليس ثمت مانع إذن من أن يكون الاتفاق في المصادر هو العلة في التشابه في النتائج خصوصاً

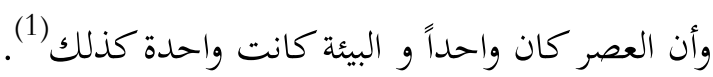
ونلخص من ذلك إلى أن الغنوصية كان لها تأثير كبير على الفلسفة وأن الأفلاطونية الجديدة آخذة عنها في غير ما موضوع مع هذا الفارق، وهو أن أفلوطين وتلامذته فلاسفة

يعولون على الاستدلال، والغنوصيون واضعوا أساطير يجرون مع الخيال (2).

2- 1- المرجع نفسه، صوسف كرم، مرجع سابق، ص260.




\section{خاتمة:}

بعد هذا العرض التاريخي النقدي لمدرسة الإسكندرية وفلسفتها الذي أوضحنا فيه الحركة الفكرية في مدرسة الإسكندرية، وأهم العوامل التي أدت إلى ظهور فلسفتها، وما هي سمات هذه

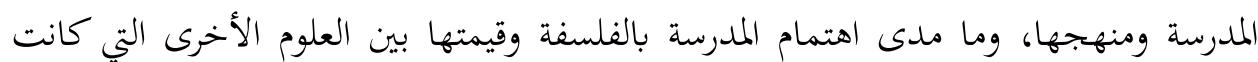

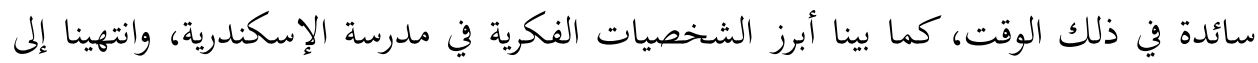
الحديث عن نشأة وخصائص أبرز تيار فلسفي يعبر عن فلسفة المدرسة، ألا وهو الأفلاطونية الجديدة وما مدى تأثر هذا التيار الفكري بالطابع الشرقي، فبعد هذا العرض يمكننا أن نذكر أبرز النتائج التي توصلنا إليها جراء تلك الدراسة وذلك على النحو الآتي: أولاً: يطلق اسم مدرسة الإسكندرية على ذلك التيار الفلسفي الذي ارتبطت نشأته بمدينة الإسكندرية.

ثانياً: في الإسكندرية التقى العالم الإغريقي أو اليوناني بالعالم الشرقي، وحدث بينهما

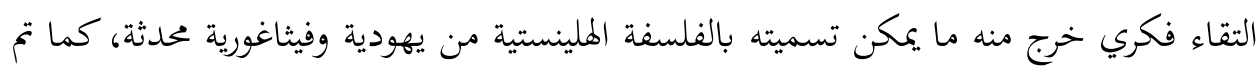
إحياء نزعة الشك (النزعة الشكية) بالإضافة إلى الأفلاطونية الجديدة أو مدرسة الإسكندرية.

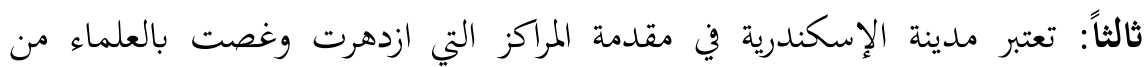
مصريين، وساميين ويونان، ورومان، فنافست أثينا وكانت حلقة اتصال بين الشرق والغرب، التربي، وازدهرت الحركة العلمية إلى جوار الحركة الأدبية.

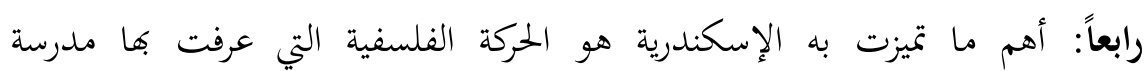

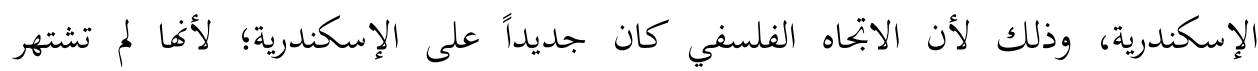
بالدراسات الفلسفية في العصر البطليمي.

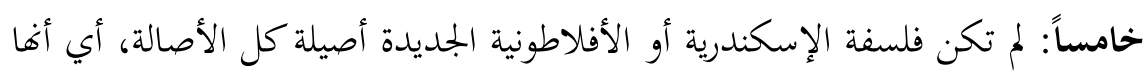

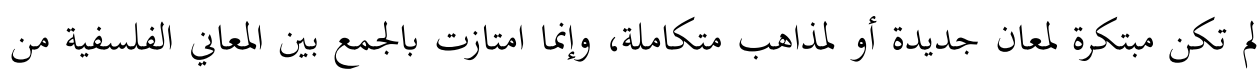
ناحية، والمعاني والقيم الدينية من ناحية أخرى وهذا ما يسمى بالتوفيق.

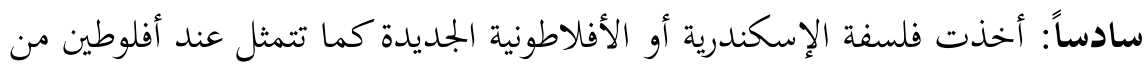


فلسفة أفلاطون ومعاني من عند أرسطو وأخرى عند الرواقيين، وبالتالي فإن فلسفة الإسكندرية

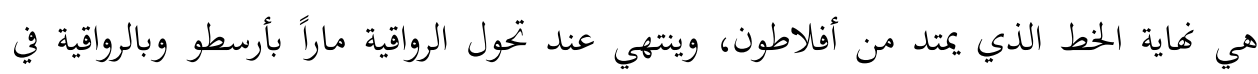
نشأما.

سابعاً: أهم ميزة تميزت بها الأفلاطونية الجديدة هي الذاتية المطلقة متأثرة بالتجربة الدينية وبخاصة التجربة الصوفية.

ثامناً: جاءت فلسفة الإسكندرية أو الأفلاطونية الجديدة تعبيراً عن روح العصر الذي

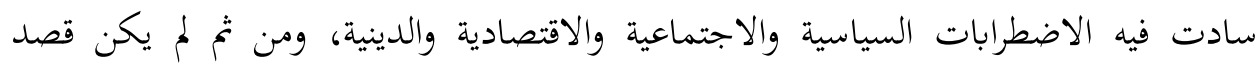

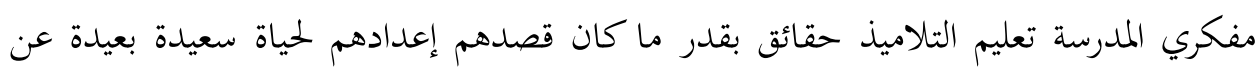
الشهوات والملذات.

تاسعاً: تأثرت فلسفة الإسكندرية أو الأفلاطونية الجديدة بالأفكار الشرقية وخاصة الفكر الغنوصي. 


\section{المصادر والمراجع العربية والأجنبية}

أولاً: العربية والمتربمة إليها:

1- أحمد أمين وزكي نجيب محمود، قصة الفلسفة اليونانية، مطبعة دار الكتب اليونانية، اليها ط: 2، القاهرة، 1970.

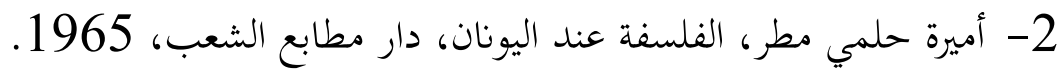

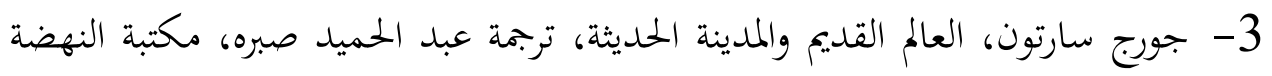
المصرية، 1960. 4- حربي عباس عطيتو، خصائص الفكر الفلسفي في حضارات الشرق القديم، دار المعرفة الجامعية، "د. ط"، الإسكندرية.

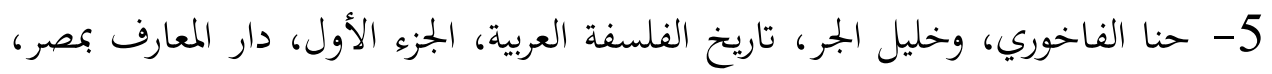
ط: 1، 1957.

6- عبد الرمن بدوي، خريف الفكر اليوناني، مكتبة النهضة المصرية، ط: 4، 1970.

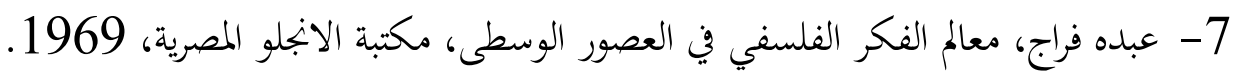

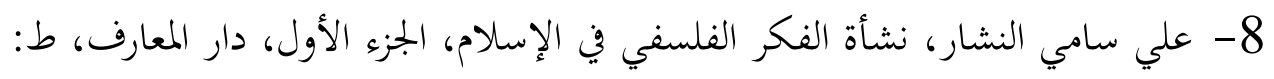
5 9- فؤاد زكريا، التساعية الرابعة لأفلوطين في النفس، مراجعة مُحّمّ سليم سالم، الهيئة المصرية العامة للكتاب، 1970. 10- ماهر عبد القادر مُحَّمَ وحربي عباس عطيتو، ابتحاهات التفكير الفلسفي في العصور الوسطى، أورينتال، الإسكندرية، 2006.

11- نجيب بلدي، تمهيد لتاريخ مدرسة الإسكندرية وفلسفتها، دار المعارف، 1962.

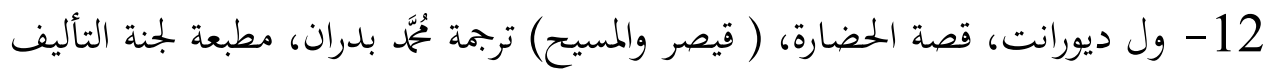
والترجمة، "د. ط". 
13- وولتر ستيس، تاريخ الفلسفة اليونانية، ترجمة مجاهد عبد المنعم مجاهد، دار الثقافة

$$
\text { 14 - يلشر والتوزيع، القاهرة، 1984. }
$$

1- Armstrong , A. H. , An Introduction to Ancieut philosophy, london 1957.

2- Carls. Meyer, The church from pentecast to the present, Chicage 1970.

3- Copleston, S.J., A history of philosophy, Greec. And Rome vol. L. New York 1962.

4- Coptic orth , Patriarchate, St Mark, cairo 1968.

5- E. Zeller, Outlines of the history of Greek philosophy, London, 1931.

6- Fr. Ueberweg, outline of philosoph, Since the beginning of Sixth century, translated by Heineze.

7- G. Bigg, Christian platonists of Alexandria, Oxford, 1913.

8- Hanz Lietzmann, A history of the Early church , London, 1974, vol 2, p186.

9- H. M. Gwaktin, Early church History, Vol 2 , London 1909.

10- J Lebreton, A history of printive church. vol. 3, London, 1946.

11- John. E. Erdmann, A history of philosophy, vol 1, Translated by W. T. , Hough.1899.p297.

12- K. S. Latourette, A history of Christianity, London 1953.

13- M. Matter, Histoir del' ecole Alex, vol. 1,2 eme de paris, 1840.

14- Quasten, Patrology, vol 1, Oxtord Dict of the Christian church.

15- Rev. Markary EL- Souriany, Ancienty and contemporary Christian Education in the coptic church, Princeton , 1955

16- Schaff, A History of Christian church, Vol.2. 1970,

17- S. Danie Lou, The Theology of Jewish Christianity, London 1964.

18- Toynbee, A., Hellenism: The history of civilization, London , 1959.

19- W. J. Cauhe, Didymus the blind, an aducatorat the forth century, Washington 1954.

$$
\text { 1- معجم الفلاسفة، المعاجم العربية جورج طرابيشي، دار الطليعة للطباعة والنشر، ط: 1، بيروت، }
$$


رابعاً: الموسوعات الأجنبية:

1- The Encyclopaedia of philosophy, art vol. 3,4, New York, 1972. 